\title{
Construção da identidade e associações italianas: La Plata e Porto Alegre (1880-1920)
}

\author{
MARÍA SILVIA OSPITAL* \\ NÚNCIA SANTORO DE CONSTANTINO**
}

Resumo: Analisando comparativamente determinadas práticas desenvolvidas por grupos dirigentes em sociedade de mútuo socorro na cidade de La Plata, Argentina, e Porto Alegre, Brasil, nas duas últimas décadas do século XIX e no início do século XX, conclui-se sobre o fundamental papel das mesmas no processo de construção da identidade italiana.

Abstract: Confronting some practices of leaders of mutual benefit societies in La Plata, Argentine, and Porto Alegre, Brazil, in the last two decades of the 19th and the beginning of the 20th century, we can see the fundamental role of them in the process of construction of an Italian identity.

Palavras-chave: Imigração. Sociedades italianas. Identidade.

Key words: Immigration. Italian societies. Identity.

O conceito de construção aplicado ao processo de formação de uma tradição, etnicidade ou identidade tem sido freqüentemente utilizado nos enfoques de história social e de história cultural. ${ }^{1}$ Fala-se também de invenção das tradições, com abordagem à tarefa propriamente dita da construção cultural e aos objetivos

.. Doutora em História, docente na Universidad Nacional de La Plata, Argentina.

Doutora em História, docente na Pontifícia Universidade Católica do Rio Grande do Sul, Brasil.

HOBSBAWM, E., RANGER, Y. T. (orgs.) The invention of tradition. Cambridge: Cambridge University Press, 1989. SOLLORS, W. The invention of Ethnicity. New York: Oxford University Press, 1989. 
perseguidos pelos "inventores" da mesma. Elementos concretos, como pessoas, objetos, lugares, que serviram de base à essa construção têm recebido pouca atenção.

O presente trabalho pretende utilizar este tipo de aproximação ao problema, qual seja, a análise do processo de edificação, para aplicá-lo a certos aspectos do discurso e das práticas desenvolvidas por grupos dirigentes da comunidade italiana em $\mathrm{La}$ Plata e em Porto Alegre. Utiliza-se especialmente a produção elaborada pelas associações mais antigas das duas cidades: "Unione e Fratellanza", em funcionamento até hoje, fundada em 1883, quando La Plata, capital da provincia de Buenos Aires, possuía apenas alguns meses de fundação; a sociedade "Vittorio Emanuelle III", na capital do estado do Rio Grande do Sul, fundada em 1877, e que, fechada durante a segunda guerra mundial, nunca foi reativada.

\section{Italianos em La Plata}

A federalização de Buenos Aires, em 1880, fez com que a província homônima precisasse ser dotada de uma nova capital para substituir a tradicional metrópole cedida à Nação. Depois de cuidadosa planificação, a pedra fundamental da cidade de La Plata foi lançada em 19 de novembro de 1882 .

Ainda que se tornando sede do governo e da administração provinciais e, conseqüentemente, ocupando importante número de funcionários e empregados argentinos, a população da cidade foi majoritariamente estrangeira durante os primeiros anos. Fontes censitárias que registraram o crescimento demográfico da urbe apontam uma proporção de estrangeiros superior a $50 \%$ até 1890 . Ainda em 1895 o índice era mantido em 45\%, e até 1914 oscilou entre 35 e $36 \%{ }^{2}$

Não são difíceis de explicar as razões da composição populacional. Fundada no início da grande expansão econômica do país, nos arredores de Buenos Aires e na mesma região pampeana que era o principal centro de atração às correntes imigratórias que fluíam à Argentina, desde décadas anteriores, uma cidade nascente oferecia múltiplas oportunidades de trabalho. As construções públicas e privadas demandavam projetistas e operários; estabelecimentos comerciais e de serviços exigiam empregados, enquanto

2 Censos Municipales: censo, marzo $1884 ; 2^{\circ}$ Censo, noviembre de $1884 ; 3^{\circ}$ Censo, octubre de 1885. Censo General de la ciudad de La Plata, 1909. Censo General de la Provincia de Buenos Aires, 1890. II Censo Nacional, 1895. III Censo Nacional, 1914. 
os recém-chegados geravam sua própria demanda de artesãos em ofícios diversos.

A "colônia" italiana foi a mais numerosa entre os grupos imigrantes estabelecidos na nova capital. Em 1884, quando se realizou o primeiro censo municipal, os peninsulares representaram mais de $50 \%$ do total de estrangeiros. Esta proporção se manteve em todas as estatísticas até 1909 . O pico máximo refletiu-se em 1885 , quando as cifras indicaram total de 10.800 italianos, um pouco mais do que o total de argentinos e equivalendo a $68 \%$ dos estrangeiros. Em 1914, o censo nacional revelou que quase a metade dos estrangeiros de La Plata ainda eram italianos, ou seja, $47 \%$.

\section{Italianos em Porto Alegre}

A origem de Porto Alegre encontra-se no povoado formado por açorianos em 1752 que, em 1822, fora elevado à condição de cidade por carta imperial. No início do século XIX o núcleo urbano crescera rapidamente, em decorrência da ampliação da lavoura tritícola, da qual era o centro exportador. Com a decadência desta lavoura, a cidade estagnou, entre 1820 e 1858, sendo reativada pelas exportações das colônias alemãs, estabelecidas nas suas proximidades desde 1824 .

Na primeira metade do século XIX, verifica-se uma intensa movimentação política na capital da Província, que concentra intelectuais, cujas idéias são veiculadas pela imprensa, depois de discutidas nas lojas maçônicas. A eclosão da Guerra dos Farrapos faz com que a cidade seja ocupada por revolucionários e faz com que, por algum tempo, republicanos italianos atuem na mesma.

A partir de 1840 há traços da presença de italianos em Porto Alegre, encontrados na imprensa, como anúncios de estabelecimentos comerciais e de óbito, e nos livros de registro de batismo da Igreja Matriz de Nossa Senhora Mãe de Deus. De 1850 em diante, esta presença é constante e, até 1914, será crescente.

Por volta de 1870 já podem ser destacados alguns elementos do grupo italiano, exercendo atividades comerciais ou artísticas. Este grupo é considerado psicossocial em forma de comunidade, pois, entre seus membros, há projeto comum, laços ideológicos, estabilidade e normas de coexistência. ${ }^{3}$ Analisando-se a trajetória 
do mesmo, a característica da estabilidade é percebida, sobretudo, pelos de laços de compadrio.

O crescimento da presença italiana e a formação de uma comunidade podem ser explicados.

A guerra contra o Paraguai oportunizara bons negócios ao comércio porto-alegrense. $\mathrm{O}$ arsenal ampliara sua produção, chegando a empregar mais de 200 trabalhadores. Foi estimulado o surgimento de indústrias e a Praça do Comércio, fundada em 1858, teve seu quadro de associados muito aumentado. Analisando-se o Almanak do Rio Grande do Sul correspondente ao ano de 1873, verifica-se que seis proprietários de estabelecimentos comerciais sediados em Porto Alegre são reconhecidamente italianos.

Desde a década de 1870 apareciam na cidade nítidos sinais de modernização. Fora introduzido o transporte urbano por tração animal e a iluminação pública a gás. A Companhia Telefônica inaugurou seus serviços; a Praça da Matriz foi embelezada com a inauguração de imponentes edifícios públicos que formaram harmonioso conjunto com o Theatro São Pedro. Fundou-se a Biblioteca Pública, inaugurou-se o primeiro trecho da estrada-de-ferro na Província, ligando a capital à zona de colonização alemã. Em trânsito passaram pela cidade, a partir de 1875, grandes contingentes de imigrantes italianos, que seguiriam para as colônias recém estabelecidas pelo governo imperial, no nordeste da Província.

Os italianos de Porto Alegre, na década de 1870, como foi dito, formaram grupo comunitário e apresentaram diferenças dos imigrantes que engrossaram os contingentes, grande maioria constituída por camponeses humildes, desprovidos de recursos, atraídos por agentes que atingiam, intencionalmente, as populações mais desamparadas do Vêneto, Lombardia, Trentino e Friuli.

Dadas as grandes dificuldades de avaliar o número de italianos fixados na cidade nas diferentes décadas do século XIX, visto que o registro da imigração era feito sem especificação de nacionalidades, mas apenas observando a categoria estrangeiros, aceitase tabelas apresentadas pelo Cônsul Brichanteau que registra para Porto Alegre, em 1891, "cerca de seis mil habitantes italianos". Tal número representa mais de $10 \%$ da população da cidade que, pelo censo de 1890, é de 52.421 habitantes.

' CONSTANTINO, Núncia Santoro de. O italiano da esquina: imigrantes na sociedade porto-alegrense. Porto Alegre: EST, 1991.

Rapporto del R. Console Cav. Avv. Edoardo dei Conti Compans de Brichanteau: Porto Alegre. Roma: Ministero degli Affari Esteri; Tipografia Nazionale di G. Bertero, 1892.

Biblioteca del Ministero degli Affari Esteri, Roma. 


\section{A primeira associação em La Plata}

A poucos meses de fundada a cidade, em junho de 1883, a incipiente elite italiana criou a primeira sociedade de socorros mútuos: "Unione e Fratellanza". Enquadrada no esquema comum dessas entidades, destinada a prestar serviços médicos e de farmácia a seus membros, a denominação, por si só, refletia uma tradição de igualitarismo e de fraternidade aparentada aos velhos ideais garibaldinos.

A recém-fundada sociedade reconhecia como modelos, nas palavras de seus primeiros dirigentes, a uma associação de socorro para desempregados existente em Milão, assim como as entidades "hermanas" de Buenos Aires. As atas, escritas em italiano culto, demonstram domínio do idioma, precisa ortografia e conhecimento das formas usuais de redação desta espécie de documentos. As ocasionais referências à pátria comum, a ausência absoluta de comentários referentes a origens ou a questões regionais, são elementos importantes para destacar. Os líderes sociais tiveram acesso à educação formal e demonstravam experiência associativa. O chamamento a sócios potenciais se dirigiu a todo indivíduo italiano, sem distinções, assentando assim as bases de uma tarefa de unificação da comunidade. ${ }^{6}$

A comunidade peninsular era numerosa na Argentina e possuía antigüidade respeitável. O associacionismo estava amplamente representado nas principais cidades, especialmente em Buenos Aires, e se havia expandido por quase todas as pequenas localidades. A relação com outras agremiações da mesma cidade, que foram sendo criadas, passou por diversas etapas.

Em 1885 funda-se a "Unione Operai Italiana", sociedade que representa fracionamento da entidade pioneira. A fratura tendeu a solucionar-se à medida que passava o tempo e, até 1891 , foram realizados em conjunto os festejos de 20 de setembro. Os dirigentes das duas sociedades também colaboraram com a associação promotora da construção de um hospital italiano em La Plata. Festas eram realizadas para tal fim, cedendo o uso do salão social e compartilhando de campanhas para arrecadação de fundos, como venda de rifas. A vinculação entre as duas entidades é perceptível, uma vez que representantes da elite italiana tomavam parte em comissões diretivas de ambas. Por outro lado, a retirada de colaboração ao projetado hospital pelos representantes da 
"Unione e Fratellanza" deveu-se à alegação de que a sociedade já oferecia serviços médicos.

O estabelecimento de laços de consorellismo entre entidades, isto é, o reconhecimento do direito a receber benefícios de sócio aos associados das entidades hermanas, foi prática largamente estendida. Na maioria das sessões do conselho diretivo aceitavam-se pedidos deste tipo, provenientes de entidades do interior da Província de Buenos Aires, Santa Fé e Córdoba e mesmo do exterior. Assim, foram mantidos laços com sociedade "Vittorio Emanuelle II”, de Porto Alegre. ${ }^{8}$

\section{A primeira associação em Porto Alegre}

Na década de 1870, os integrantes do grupo comunitário italiano em Porto Alegre estão conscientes de sua nacionalidade, acompanham os feitos do ressurgimento italiano e cultuam heróis da pátria de origem, como Garibaldi, por sua atuação nos dois mundos, inclusive no mundo rio-grandense, durante a Revolução Farroupilha. E, como comunidade, fundam a Sociedade "Mutuo Soccorso e Benevolenza", em $1^{\circ}$ de julho de 1877 , nome que, em março do ano seguinte, em assembléia de sócios, é mudado para "Vittorio Emanuelle II", homenageando o rei recentemente falecido. Os estatutos são redigidos ainda em 1877, sendo aprovados pelo Governo Provincial somente em1882.

A iniciativa deveu-se a expoentes da mesma comunidade, e destinou-se, em primeiro lugar, a promover o socorro mútuo. Mas, ainda no ano de sua fundação, a diretoria escolheu Garibaldi como presidente de honra e do general recebeu carta de agradecimento. Investigação em torno dos elementos que formaram o quadro social permite concluir que os mesmos eram destacados e prestigiados no comércio e nas artes. ${ }^{9}$

Os estatutos da sociedade são aprovados e publicados em 1882. Prevêem número de sócios ilimitado, desde que fossem italianos, nascidos em solo italiano ou nas províncias ainda não unificadas, ou ainda fossem filhos de italianos, mesmo quando naturalizados. Seria admitida como sócio honorário a "pessoa que por

A comissão conjunta da Unione e Fratellanza com a Sociedad Hospital Italiano funcionou a partir de maio de 1891 e foi-se diluindo até o final do mesmo ano.

O consorellismo com a entidade brasileira concretizou-se em janeiro de 1892.

Id. Gli emigranti dall Italia del sud a Porto Alegre: studio di storia sociale. In: TRENTO, Angelo (org.) La Presenza italiana nella storia e nella cultura del Brasile. Torino: Fondazione Giovanni Agnelli, 1991. p. 263-283. 
ações nobres e generosas tenha merecido a estima da humanidade e da colônia italiana de Porto Alegre". Como sócios por mérito, seriam distinguidos médicos e farmacêuticos que se comprometessem a atender, sem cobrança de honorários, pelo menos uma parte dos sócios e que ainda a estes fornecessem gratuitamente os medicamentos necessários; advogados que protegessem gratuitamente associados, sócio que fizesse doação superior a cinqüenta mil réis. Foram objetivos estabelecidos à sociedade: unir todos os italianos estabelecidos em Porto Alegre; promover o bem-estar dos sócios; socorrer os mesmos na doença; pagar despesas de enterros; auxiliar na procura de trabalho.

Posteriormente a sociedade promoveu campanha para a construção do "Hospital Italiano Regina Margherita", obtendo terreno por doação e arrecadando fundos que, por insuficientes, mais tarde serviriam à construção da sede própria. A diretoria pleiteou tal sede, seguindo o exemplo da Sociedade "Humberto I”, surgida em 1900 e em edifício próprio desde 1904, no mesmo ano em que se inaugurou o belíssimo prédio da "Vittorio", no centro da cidade. Quatro anos depois, outra sociedade inauguraria sua sede própria. Trata-se da "Principessa Elena de Montenegro", que surgira em 1893, com o nome de "Bella Aurora", mudado por ocasião do casamento de Príncipe de Nápoles.

Como se percebe, a diversificação ou fragmentação da colônia era fato, melhor exemplificado ainda quando citadas outras sociedades que alcançaram relativa permanência, como a Giovanni Emanuel, fundada em 1902, ou o Sodalizio Giuseppe Mazzini, estabelecido no arrabalde da Tristeza, então zona de veraneio, já em 1885. Em 1907, fundou-se o Club Italiano Canottieri Duca degli Abru$z z i$, com finalidades esportivas, sobretudo remo, ginástica e natação. A Società Nazionale Dante Alighieri teria sua sucursal em Porto Alegre a partir de 1914 , com finalidades educacionais e culturais. ${ }^{11}$

As dissidências eram conhecidas e lamentadas, inclusive através da imprensa. Em campanha promovida pelo estabelecimento da sociedade Dante Alighieri, comenta o diretorproprietário do jornal Stella d'Italia, A. Colnaghi, em 1914, as divergentes opiniões dos concidadãos sobre apoiar ou não a iniciativa, destacando com júbilo que o partido dos que apóiam é majoritário; menciona ainda experiências passadas que resultaram no

10 RIO GRANDE DO SUL. Actos do Governo da Província do Rio Grande do Sul de 1882. Porto Alegre: Officina Typographica de Carlos Echenique, 1908. p. 6-21.

"Cinquantenario della colonizzazione italiana nel Rio Grande del Sud: 1875-1825. Porto Alegre: Globo; Roma: Ministero degli Affari Esteri, 1925. p. 364-376. 
"fiasco da Federazione delle Societá". ${ }^{12}$ Através da mesma matéria é possível perceber que, enquanto a "Elena de Montenegro" adere com presteza ao projeto, a "Vittorio" tarda para, por fim, incorporar-se ao comitê que organizaria a nova sociedade, criada para divulgar o idioma italiano.

\section{Símbolos, edifícios, festas}

A premência para construir uma sede própria impõe-se à diretoria da "Vittorio" quando a sociedade "Umberto I" inicia a construção do seu prédio. Os fundos arrecadados para o Hospital Italiano, insuficientes ao empreendimento, servirão para iniciar as obras do edifício próprio em terreno adquirido em rua central da cidade.

Às duas horas da tarde do dia 3 de julho de 1904, em cerimônia prestigiada por representantes do presidente do estado, pelo intendente municipal, por representante do distrito militar e pelo cônsul geral, cerimônia assistida por grande número de jornalistas e convidados, houve sessão solene de inauguração do palacete, dirigida pelo Cel. Aurélio de Bittencourt, que representava o presidente do estado. Encerrados os discursos, houve "vivas à Itália e ao Brasil", e os brindes foram acompanhados pela música da banda do $1^{9}$ Batalhão da Brigada Militar. ${ }^{13} \mathrm{O}$ presidente da sociedade vendera o terreno destinado ao hospital para dar início às obras, no ano anterior; sua decisão foi objeto de elogios, sobretudo por parte de autoridades italianas, pois esta sede passou a ser considerada como imóvel "mais precioso moralmente do que materialmente" ou ainda "edifício soberbo" que conferia "decoro" e atendia a "aspirações". Giovanni Berutti, então presidente da Vittorio, foi muitíssimo elogiado pela "obra grandiosa que lhe custou sacrifícios e humilhações". À construção foram oferecidos serviços gratuitos de sócios: a supervisão técnica foi responsabilidade dos conhecidos construtores Pietro Bonotto, Paolo Paganini, Ermenegildo Dani, Vittorio Ferlini e Luiggi Macchi. ${ }^{14}$

Através de fotografias pode-se admirar a imponência da construção de dois pisos, em estilo neoclássico com parte da fachada em mármore, seis aberturas frontais e sacadas de ferro, sendo que as três portas do piso superior encontravam-se emolduradas e guarnecidas, na parte superior, por nichos com bustos de

12 Stella d'Ttalia, n. 1232, 29 jan. 1914, p. 1.

13 A Federação, Porto Alegre, 4 jul. 1904.

14 Cinquantenario, op.cit., p. 366-367. 
personalidades italianas; destacava-se o frontão de estuque, encimado por alegoria à pátria distante. Como todas as sociedades italianas no Brasil, foi impedida de funcionar e lacrada durante a Segunda Guerra, sendo sua documentação apreendida e, posteriormente, extraviada ou perdida no incêndio da Repartição Central de Polícia. A Vittorio nunca foi reaberta e, nos anos setenta, o prédio foi vendido e demolido.

Durante os quarenta anos em que a sociedade funcionou na sua sede à Rua Sete de Setembro, serviu como referência à vida social da cidade, promovendo e destacando a coletividade peninsular. Nas suas dependências eram recebidas personalidades italiana visitantes, como, por exemplo, o tenor Annibale Bonomi, da companhia de operetas Città de Firenze, a quem foi oferecida "uma opípara ceia regada a vinho e champagne". ${ }^{15}$ Ou o sociólogo Enrico Ferri, fotografado com sua "exma. esposa, cercado de membros salientes da colônia italiana [...] e alguns cavalheiros patrícios", depois de conferência sobre criminalística, que "deixou a mais funda impressão no espírito dos intelectuais de Porto Alegre". 16 Também Anita Italia Garibaldi, "neta do herói dos dois mundos", de visita à cidade para coleta de dados para um livro que escreveria sobre o avô, recebeu cumprimentos da diretoria da Vittorio e a cópia fotográfica da carta que o mesmo enviara, agradecendo o título de presidente de honra da sociedade, no ano de sua fundação. ${ }^{17}$ Famosas eram as festas campestres promovidas. O congraçamento iniciava na sede central, com convocações através da imprensa, de onde os sócios saíam para áreas rurais, como em 15 de março de 1914, quando excursionariam a pé até o "Bosco Mostardeiro, gentilmente concesso", acompanhados da Banda de Música do $10^{\circ}$ Regimento; no programa constava grande número de jogos e diversões. ${ }^{18}$

Também através da imprensa eram publicados os balanços da sociedade, cujos fundos eram depositados no Banco da Província e no Banco do Commercio. Da mesma forma, o resultado de auditorias financeiras aparecia estampado: "Abbiamo scrupolosamente esaminata la gestione [...] e abbiamo trovato tutto in perfectto ordine", eram palavras seguidas por felicitações ao tesourei-

\footnotetext{
Jornal da Manhâ, Porto Alegre, 4 jul. 1904.

O Independente, Porto Alegre, 22 dez. 1910.

Correio do Povo, Porto Alegre, 10 mar. 1929.

${ }^{18}$ Stella d' Italia, Porto Alegre, 15 mar. 1914.
} 
ro. ${ }^{19}$ A imagem de eficiência e de probidade, assim, sendo divulgada, permanecia preservada.

Tal imagem, entretanto, solidifica-se nas recepções diversas e bailes concorridos, festas que fazem parte da memória dos que as freqüentaram. Comemorou-se com estilo datas cívicas italianas e brasileiras, com louvores a heróis binacionais. Em conclamações através da imprensa, a sociedade engajou-se em campanhas que se desenvolviam no Brasil e na Itália.

O aniversário de fundação da Vittorio sempre foi motivo para longas matérias na imprensa porto-alegrense. Por exemplo, no ano do cinqüentenário, noticiavam-se os festejos, elogiando o entusiasmo do baile e a excelente "hora de arte", momentos oferecidos á coletividade. Na matéria, recorre-se à infalível reprodução fotográfica da carta de agradecimento escrita por Garibaldi. ${ }^{20}$ Quando a sociedade completava 49 anos de existência, apresentou-se o histórico da mesma, com destaque à inauguração da placa de mármore homenageando Garibaldi, em 1907, ano do centenário do seu nascimento. $\mathrm{Na}$ mesma matéria, mais uma reprodução fotográfica da famosa carta. ${ }^{21}$

Naquele ano, por iniciativa da diretoria da sociedade, formara-se comitê para organizar homenagens: "Desta grande apoteose do herói dos dois mundos", surgiu a idéia de oferecer ao Rio Grande um monumento, "no qual as figuras legendárias de Garibaldi e de Anita Ribeiro atestassem a afinidade étnica e histórica que liga, indissoluvelmente, com vínculo de amor e de sangue, italianos e rio-grandenses". Tratou-se da coleta de fundos, e a execução do mesmo foi encomendada à firma Fratelli Giorgini, de Livorno, por 25.000 liras. Em 1913, no dia 20 de setembro, também data máxima dos rio-grandenses, que comemoram o início da Revolução Farroupilha, inaugurou-se a estátua de Garibaldi com Anita, na praça que passou a ter o nome do general. À festa compareceram representações de mais de trinta associações italianas no Estado, com suas bandeiras tricolores; registrou-se a presença das principais autoridades estaduais, como o governador Borges de Medeiros, e italianas, como cônsules e agentes consulares.

Sabe-se que a identidade étnica é uma construção cultural que se realiza em um período de tempo histórico; grupos étnicos se recriam constantemente e a etnicidade é sempre reinventada

19 Ibid., 15 jan. 1914.

20. Correio do Povo, Porto Alegre, 5 jul. 1927.

2t Correio do Povo, Porto Alegre, 11 jul. 1926.

2 Cinquantenário, op. cit., p. 407-408. 
para fazer frente a realidades que mudam. ${ }^{23}$ Ademais, a identidade pode ser lida através de um conjunto de signos que são indicadores dos limites da mesma identidade. ${ }^{24}$

A utilização de símbolos é claramente perceptível no processo de instalação da sociedade italiana de La Plata, dentre os quais o edifício que se pleiteava construir.

Desde as primeiras atas registradas pela diretoria da Unione e Fratellanza, verifica-se a preocupação pela instalação em sede própria. Nos primeiros tempos funcionou em dependência de um depósito de grãos, depois transferiu-se para uma casa que foi emprestada, onde permaneceu até inaugurar-se o edifício social, com grande salão de atos e escritórios diversos. Longas discussões constam nestas atas sobre a localização mais apropriada, a melhor forma de construção e de elementos decorativos que adornariam o prédio. $^{25}$

A obra foi encomendada a uma comissão de sócios construtores, ofício altamente representado entre os italianos. Também foram peninsulares os ferreiros e tapeceiros que proporcionaram as grades da entrada e os cortinados do grande salão. Em 1889, a construção foi terminada e promoveu-se faustosa cerimônia de inauguração. ${ }^{26}$ A partir desta inauguração, ficou evidente para todos em La Plata, estrangeiros ou nacionais, residentes ou de passagem, a imponente presença da Sociedade de Socorros Mútuos Unión y Fraternidad, nome que já havia sido inscrito na fachada do prédio anterior, modesto e emprestado.

A convicção sobre a importância do uso de símbolos na conformação de uma imagem representativa manifestou-se desde os primeiros momentos de funcionamento da entidade. Poucos meses depois de fundada, sugeriu-se aos sócios que içassem bandeiras para comemorar, na festa de 20 de setembro. Tal convicção é confirmada pela decisão de dotar a sociedade de um estandarte próprio, para presidir desfiles das delegações em todos os atos

${ }^{23}$ CONZEN, Kathlen Neil et. al. The invention of ethnicity: una lettura americana. Altreitalie, Turim, n. 3, ano 2, abr. 1990.

24 DI CARLI, Angelo \& Serena. I luoghi dell 'identità. Milão: Angeli, 1986, p. 183-184.

25 Ata de 26 de julho 1883,27 de janeiro de $1884 ; 22$ de junho de 1885 , quando se inscreve o nome da sociedade na fachada da sede provisória; agosto de 1887.

26 Sobre a construção do novo edifício, as conversas iniciaram em setembro de 1887 . A compra do terreno concretizou-se em maio de 1888. Apresentaram-se diversas propostas à construção, sendo aceita aquela do construtor G. Landó. Em julho de 1888, o presidente G. Marelli recebeu autorização para solicitar empréstimo ao Banco Hipotecario Provincial para financiar a obra. 
públicos em que a sociedade participasse. A honra de portar esta insígnia era distinção outorgada a sócios destacados. ${ }^{27}$

Se, num primeiro momento, a comissão diretiva se distinguia publicamente mediante este estandarte, em 1891 estarão figurando junto ao mesmo as bandeiras italiana e argentina. Supõe-se que, já significativo o número de sócios e reconhecida por estranhos, a instituição permitia mostrar-se como a representante dos italianos na cidade de La Plata, tornando mais completa e complexa sua imagem pública. ${ }^{28}$

Ações destinadas a manifestar uma identidade própria podem ser analisadas em conjunto com oportunidades e maneiras com que a sociedade festejava aniversários e datas importantes. $\mathrm{O}$ edifício social se engalanava com bandeiras, era feérica a iluminação dos salões onde se realizariam atividades oportunamente decididas pela comissão diretiva. O programa de festas mantinha padrão semelhante: discursos comemorativos, recepção a autoridades, rifas para obtenção de fundos, grande baile ao final. Espetáculo pirotécnico e atuação de uma banda de música eram elementos infalíveis em qualquer oportunidade. A estes festejos estavam convidados os sócios e ogni connazionale che volesse prendervi parte. Importante destacar a maneira com que se considerou a festa de 19 de novembro, aniversário da fundação de La Plata. Em 1885, na discussão sobre formas apropriadas para comemorar o 20 de setembro, resolveu-se reservar a saudação ao governador provincial para o 19 de novembro. A primeira data citada relacionava-se aos italianos, de modo específico; a segunda era "puramente" dos argentinos platenses. Assim, concluiu-se que um e outro aniversário exigiam diferentes cerimônias. Entretanto, em 1891, a proposta sobre o festejo de 19 de novembro foi um baile, no estilo dos que se realizavam por ocasião do aniversário da entidade. ${ }^{29} \mathrm{~A}$ fundação de La Plata seguia sendo a "festa citadina", mas então já era possível festejar de modo semelhante ao utilizado para um acontecimento próprio da colônia.

Estas festas, sem dúvida, eram ocasiões em que os objetos simbólicos funcionavam em uníssono; bandeiras, edifício e música eram conjugados para reforçar os traços culturais italianos.

${ }^{27}$ Ata de setembro de 1886, convidando as sociedades italianas de La Plata para a festa de inauguração do estandarte social.

28 Ata de 8 de setembro de 1891; o festejo reuniria as duas mais antigas associações italianas em La Plata.

29 Atas de setembro de 1884 , abril de 1887,15 de setembro de 1888 , dezembro de 1888 ; abril de 1891 . 
A par do estabelecimento de laços de "consorellismo" entre entidades de outras cidades e países, que representa a permanente tentativa de aglutinação de uma comunidade italiana, a vinculação institucional se estende no espaço das transações financeiras. A poupança e o depósito dos frutos de um esforço diário em lugar seguro eram questões fundamentais para os sócios, comerciantes e operários imigrantes. Os líderes sociais tinham muito claras as preocupações e manifestavam seu zelo com a contabilidade. Nos primeiros tempos, para depositar as economias, a entidade recorreu ao Banco de la Provincia de Buenos Aires, única instituição com sucursais na cidade até 1888 . Mas, no final deste ano, estabeleceu-se em La Plata um escritório do Banco de Italia y Rio de La Plata, para onde a comissão diretiva da sociedade decidiu transladar a conta social. As razões que fundamentaram tal resolução teriam sido "uma vantagem pecuniária e, sobretudo, o espírito de patriotismo".

A relação estreita com o banco italiano, principal canal condutor das remessas dos imigrantes à pátria de origem, foi reforçada durante a gestão do presidente Victor Boggiano, na década de 1890. Este comerciante e importador foi membro da junta consultiva do Banco de Italia y Rio de La Plata, assim como gerente da sucursal platense a partir 1899. A instituição financeira, por gestões do próprio Boggiano, concedeu empréstimo que permitiu saldar hipoteca que a mutual mantinha com o banco provincial desde a época da construção da sede própria. A comissão diretiva tratou de manter alijada das reuniões a eventual competição entre instituições bancárias, evitando designar uma ou outra no Estatuto. Mas se expressava claramente a obrigação de manter a receita nas mãos de instituições financeiras italianas.

\section{Considerações finais}

A presente síntese pretendeu refletir aspectos do processo de construção de uma identidade italiana, mediante utilização de símbolos e da ocupação do espaço público. Analisou-se duas sociedades italianas estabelecidas em cidades de países limítrofes, Argentina e Brasil, no intervalo de seis anos, sendo a brasileira mais antiga, fundada em 1877.

Em 1883, quando a Unione e Fratellanza surgiu, La Plata era uma cidade recém fundada. A comunidade peninsular, entretanto,

30 Atas de dezembro de 1888 . 
tornou-se de imediato numerosa. Na Argentina esta comunidade possuía antigüidade respeitável, sendo que o associacionismo estava de modo amplo representado, especialmente em Buenos Aires, embora houvesse se expandido por todas as pequenas localidades.

Já Porto Alegre era cidade antiga, de escassa presença estrangeira. Um pequeno grupo de italianos nela encontra-se estabelecido em meados do século passado e será paulatinamente ampliado a partir da década de 1850 . O associacionismo é novidade, e a $V i$ ttorio é a segunda sociedade fundada no Rio Grande do Sul, antecedida por aquela fundada em Bagé, na fronteira com o Uruguai, em 1871. A primeira sociedade italiana no Brasil foi criada no Rio de Janeiro em 1851, mas a quase totalidade das sociedades em território brasileiro apareceu na década de 1880 .

$\mathrm{E}$, se diferentes características de grupos imigrantes encontram-se na origem das duas sociedades analisadas, seus associados acionaram estratégias semelhantes com a finalidade de identificarem-se e de serem identificados.

Edifícios e bandeiras foram objetos de forte presença física e de poderoso significado. Demonstraram a importância de instituições de italianos nas cidades, ao mesmo tempo em que auxiliaram na ocultação das possíveis fissuras ou enfrentamentos no interior da coletividade. Cumpriram assim a função de oferecer uma imagem de unidade, com elementos facilmente relacionados ao conjunto dos italianos. Aproximações e distanciamentos inscrevem-se na processo associacionista italiano nas duas cidades em questão, pois as formas em que se assumia a identidade comum encontrava limites na defesa das prerrogativas de cada instituição.

A edificação de uma imponente sede social em zona central das cidades e a participação em atos que reuniam multidões, portando estandartes e bandeiras, foram práticas concretas de ocupação do espaço público. Tais ações, destinadas a colocar em manifesto uma identidade, podem ser analisadas em conjunto com oportunidades e modos como as sociedades festejavam aniversários e datas importantes. Ademais, as diferenças que tais práticas apresentaram no decorrer do tempo, comprovam que a reinvenção de identidades foi processo contínuo.

Fizemos referências a formas de apresentação relacionadas a estandartes e a bandeiras. Num primeiro momento, a sociedade de La Plata mostrava-se em público somente com seu estandarte. Era modo de distinguir-se no interior da comunidade peninsular, de fortalecer sua presença na nova cidade e entre os patrícios recém reunidos. Poucos anos depois, a bandeira italiana engalanava 
Construção da identidade e associações italianas: La Plata e Porto Alegre... 145

a fachada da sede social e, em atos públicos, se agregava à bandeira argentina, como terceiro elemento destinado a impressionar especialmente os setores dirigentes da sociedade receptora.

As fontes disponíveis à pesquisa da Vittorio revelam, nas primeiras décadas de sua existência, a permanência de símbolos que evidenciam uma forma de nacionalismo italiano militarpatriótico. A sociedade assumiu tal caráter sob a égide de figuras proeminentes do novo estado italiano, como é o caso do rei que lhe empresta o nome e de Garibaldi, como herói nas guerras de unificação. Assim, representou a Nova Italia, para atingir a meta de congregar e representar os italianos na cidade. Este culto a Garibaldi seria continuamente revitalizado, pois na virada do século desenvolvia-se no Estado um movimento regionalista, tendo como ponto de partida a Revolução Farroupilha, na qual o mesmo Garibaldi tomara parte. Se antes o herói dos dois mundos era representado com a farda de general, num segundo momento vestiu o poncho dos gaúchos.

Os primeiros imigrantes utilizaram sociedades porque precisavam afirmar-se na sociedade rio-platense e porto-alegrense, além de prestarem mútuo socorro; num segundo momento, utilizaram as mesmas sociedades para fazerem parte, para promoverem assimilação, o que foi possível através de elaboradas negociações com a cultura autóctone, intermediados por símbolos.

Pensamos que algumas das práticas das sociedades Unione e Fratellanza e Vittorio Emanuelle, assim como as respectivas reflexões sobre as mesmas, exemplificam o processo de construção da imagem da identidade italiana que os dirigentes sociais, sem dúvida, levaram a cabo. 